\title{
Comparison between a Simple and a More Complex Zone Model in Fire Engineering
}

\author{
STAFFAN BENGTSON
}

The Swedish Fire Protection Association

Sweden

\section{BENGT HÄGGLUND}

National Defence Research Institute

Sweden

\section{FREDDY MADSEN}

The Danish Fire Protection Association, DFPA

Denmark

\section{ABSTRACT}

In this paper the calculation of critical events in a fire situation defined as time for smoke logging and flashover is shown using two different fire models. Two models were used, a revised DFPA version of the simple model ASETB and the more complex model DSLAYV. Both of these are single-room models. They assume near-floor-elevation leakage and they have a capability for simulating the effect of ceiling ventilation to the outside ambient. In using the two models, the difference in calculated times is never larger than $15 \%$ showing that ASETB works well as an engineering tool. The error which occurs when you are using wrong description of the fire growth is much larger.

\section{INTRODUCTION}

By different reasons there has been a growing demand in fire engineering to create models by which it's possible to predict the effect of a fire in it's first stages.

A lot of different fire models has been created during the last decades with changing degree of complexity. In this article the outcome of a more simple method is compared with a more complex method. The reason for using the simple model is that it can be handled with a simple personal computer and that means that many calculations can be performed very quickly at a low cost, so that using fire models in design of fire safety is not restricted to large or prestige buildings.

\section{A SHORT DESCRIPTION OF THE SIMULATION MODELS}

In the two models $\operatorname{ASETB}(1,2,3)$ and $\operatorname{DSLAYV}(4,5)$ the technique to divide the fire room in two zones with different temperatures is used.

The outlay which also accounts for roof-venting is described in Figure 1 and 2. For given values of the vent area the model predicts the depth and temperature of the smoke layer. 

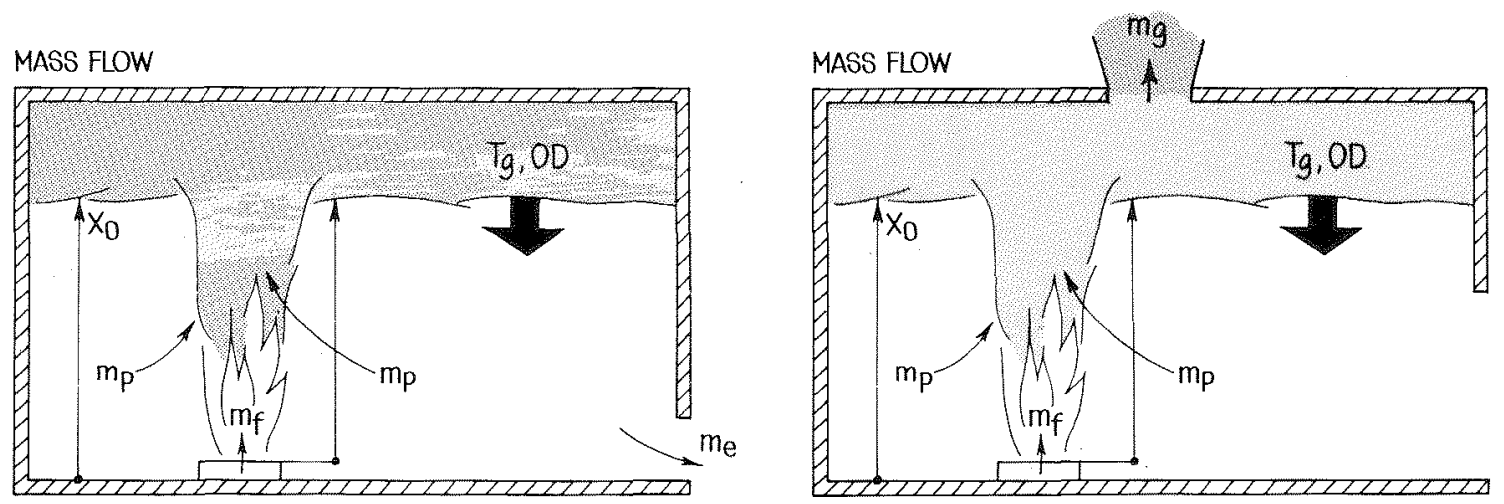

$\stackrel{\text { N }}{ }$
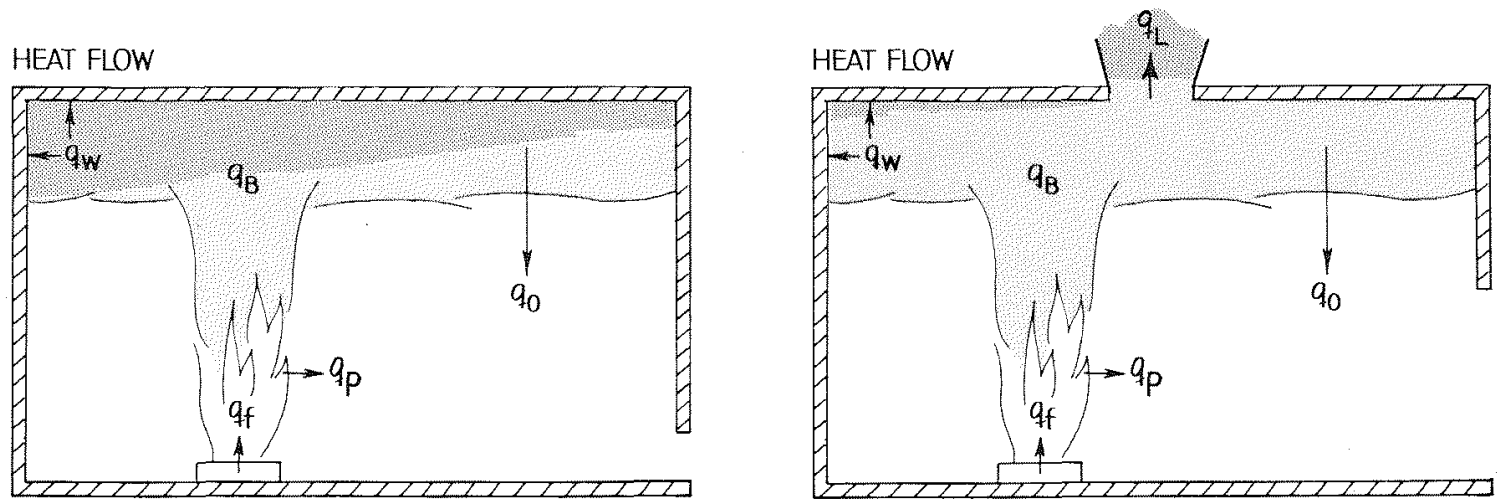

Fig. 1 The smoke filling simulation model.

Fig. 2 The smoke filling simulation model including the effect of fire ventilation. 
Input data common for the two models are the geometry of the room and the heat release of the fire.

In DSLAYV the heat and mass flow is calculated by solving the conservation equations for the two layers. To do these calculations you need a computer with a capacity of the order $1 \mathrm{Mb}$.

In ASETB some simplifying assumptions are made. To calculate the temperature and the total mass flow in the plume a dimensionless value $\left(Q^{*}\right)$ of $Q$ (rate of the fire's energy release) is used (eq 1 ) $Q^{*}=\left(1-\lambda_{r}\right) Q /\left[\rho_{a} C_{p} T_{a}(g z)^{\frac{1}{2} z^{2}}\right]$ eq 1

where $\lambda_{\mathrm{r}}=\underset{\substack{\text { effective } \\ \text { zone }}}{\Omega_{\text {fraction }}} \mathrm{Q}$ radiated from the combustion

$\rho_{a}=$ ambient density $\left(\mathrm{kg} / \mathrm{m}^{3}\right)$

$\mathrm{C}_{\mathrm{p}}=$ specific heat capacity $\left(\mathrm{J} / \mathrm{kg},{ }^{\circ} \mathrm{C}\right)$

$\mathrm{T}_{\mathrm{a}}=$ ambient temperatur $\left({ }^{\circ} \mathrm{K}\right)$

$g=$ acceleration of gravity $\left(9.81 \mathrm{~m} / \mathrm{sek}^{2}\right)$

$z \quad=$ elevation $(\mathrm{m})$

Cooper has in ASETB assumed $\lambda_{\text {r }}$ to be constant and having the value 0.35 . In that way $65 \%$ of the total heat release is convected upward and used to raise the temperature of the smoke layer.

To make the calculations simple it's also necessary to give a constant value to $\lambda_{\text {. which is defined as the combined instantaneous }}$ fraction of $Q$ lost by the combustion zone, the plume gases, and the hot upper layer gases to the bounding surfaces of the room and it's contents. $\lambda_{c}$ is made up of radiation losses and convection losses. Cooper recommends $\lambda_{c}$ values between 0.6 and 0.9 .

Included orginally in DSLAYV was a capability of modeling ceiling ventilation. This involves use of

$m_{c}=c_{d} A_{c} S_{o} \quad\left\{2 T_{o} / T_{g}\left(1-T_{o} / T_{g}\right)\left(H-x_{D}\right)\right\}^{1 / 2}$ eq 2

$\mathrm{m}_{\mathrm{c}}=$ rate of out flow of hot gases through the vent, $\mathrm{kg} / \mathrm{s}$

$A_{c}=$ area of vent opening $\left(\mathrm{m}^{2}\right)$

$\mathrm{C}_{\mathrm{d}}=$ vent opening flow coefficient

$\mathrm{H}=$ height of room (m)

$\mathrm{X}_{\mathrm{D}} \quad=$ height of smoke layer (m)

$\mathrm{T}_{\mathrm{O}}=$ ambient temperature $\left({ }^{\circ} \mathrm{K}\right)$

$\mathrm{T}_{\mathrm{g}}=$ temperature of hot gases $\left({ }^{\circ} \mathrm{K}\right)$ 
Use of the above requires that the near-floor leakage path involves an area large enough for the pressure at the floor of the room to be virtually identical to the outside ambient pressure.

We have used eq 2 to add a ceiling ventilation capability to ASETB which was not included in its original version. The DSLAYV model and this revised ASETB model were used in comparision calculations which are described below.

\section{COMPARTSONS}

In the following the lower level of the smoke layer and its temperature calculated by the two different methods is compared when using different input parameters. The difference in calculated times to critical events, smoke logging and flashover is also presented.

\subsection{Input data}

In table 1 is the different input data for the 26 runs shown. The fire has been described by an exponential growing fire (eq 3 )
$Q(t)$

$$
=Q_{0} \exp ((\ln 2) \quad t / d)
$$
eq 3

where

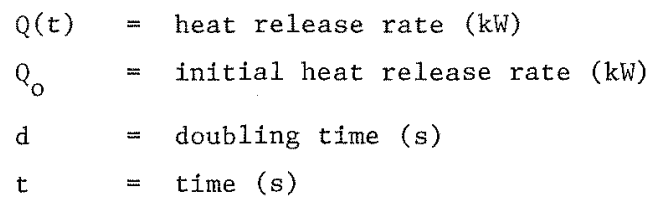

$t_{f y}$ in table 1 is the time when the ceiling vents are opened. When non-zero-area celling vents are simulated in the calculations, $t_{f v}$ and $\mathrm{C}_{\mathrm{d}}$ of eq 2 are always taken to be $300 \mathrm{~s}$ and 0.6 respectively.

\subsection{Results from DSLAYV}

In fig 3 (run 19, 20,21) is shown the effect of varying the ceiling height from 4 to $10 \mathrm{~m}$ in a rgom with the floor area $1000 \mathrm{~m}^{2}$ and with real fire vent area $10 \mathrm{~m}^{2}$.

The doubling time is $120 \mathrm{~s}$.

The $\lambda$-value calculated in DSLAYV in these runs varies between 1.0 and 0.7 .

other runs show that a wrong guessing of the doubling time and initial heat output value gives very large discrepancies in the calculated values. 

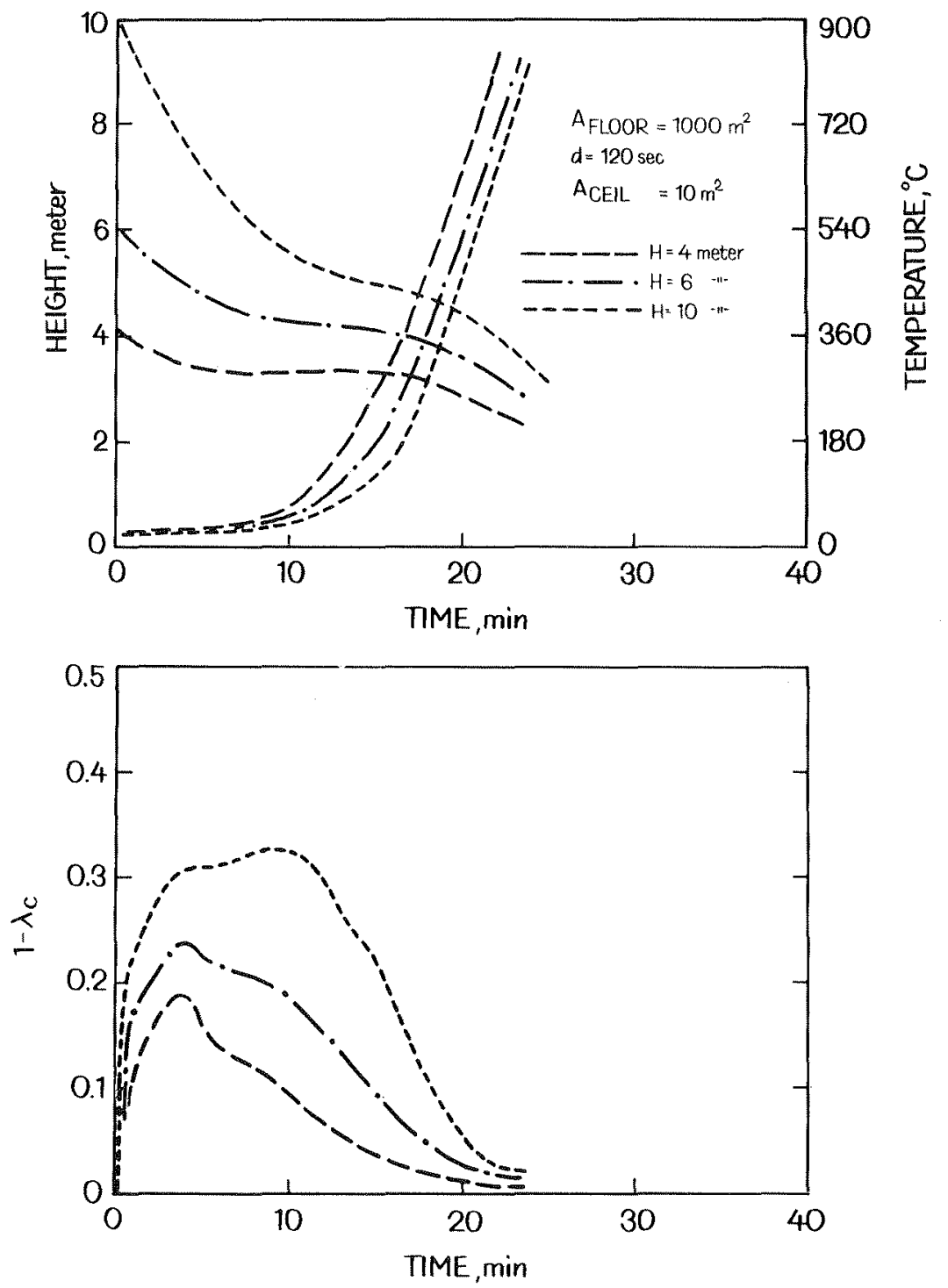

Fig. 3 The level of the smoke layer and the temperatures in runs 19,20 and 21 . 


\subsection{Results from ASETB}

In running ASETB a constant $\lambda_{c}$-value of 0.8 has been used.

In fig 4 and 5 is shown the smoke layer and its temperature calculated by ASETB and DSLAYV in runs 19 and 21 (fig 4 ) and 8 and 10 (fig 5). From the figures can be seen that the difference in prediction of the smoke layer is quite small. The difference in temperature at a specific time is larger especially when using fire ventilation and at larger doubling times. Now this difference isn't of great importance but differences between time to critical events. This is described in the next section.

\subsection{Time to critical events}

Different judgements can be used to quantify a critical event when escape isn't possible and fighting a fire is difficult and dangerous. In this paper time until the smoke reaches $3 \mathrm{~m}$ from the floor and when the temperature of the hot layer is higher than $600{ }^{\circ} \mathrm{C}$ have been used. In table 2 times until these critical events are occurring is presented.

As can be seen from table 2 the differences which are defined as value (DSLAYV)-value (ASETB) are never larger than $15 \%$ of the DSLAYV-value.

A wrong value of the doubling timed gives much larger differences. In run 8,9 and 10 the time until the smoke reaches $3 \mathrm{~m}$ above the floor is 820,1050 and 1540 seconds, respectively. The doubling times used are 120,240 and 360 seconds. The error can be of the magnitude $20-50 \%$ if there is a difference of 2 minutes in the doubling times.

A wrong guess of the initial heat release (run 9 and 18) can also give a difference of $50 \%$ in calculated time until a critical event.

\subsection{Conclusions}

As can be seen from 3.4 the differences in calculated time by ASETB and DSLAYV until critical events occur are of the order $15 \%$.

In these calculations important parameters has been greatly varied. The error is much larger when using the wrong heat release rate described by doubling time and initial heat release rate.

This fact indicates that ASETB can be used as an engineering tool with good accuracy.

Further efforts should therefore be directed to the description of fire growth instead of giving more detalls to fire models. 
TABELL 1 Input data

\begin{tabular}{|c|c|c|c|c|c|c|}
\hline $\begin{array}{l}\text { Run } \\
\mathrm{Nr}\end{array}$ & $\begin{array}{c}\text { Floor } \\
\text { area } \\
\mathrm{m}^{2}\end{array}$ & $\begin{array}{l}\text { Room } \\
\text { height } \\
\text { (m) }\end{array}$ & $\begin{array}{c}\mathrm{D} \\
(\mathrm{s})\end{array}$ & $\begin{array}{c}Q_{0} \\
(\mathrm{~kW})\end{array}$ & ${ }_{\left(m^{2}\right)}^{A}$ & $\begin{array}{l}t_{f v} \\
(s)\end{array}$ \\
\hline 1 & 200 & 4 & 120 & 50 & 10 & 300 \\
\hline 2 & 200 & 10 & 360 & 50 & 10 & 300 \\
\hline 3 & 200 & 4 & 120 & 50 & 0 & - \\
\hline 4 & 200 & 10 & 360 & 50 & 0 & - \\
\hline 5 & 1000 & 4 & 120 & 50 & 25 & 300 \\
\hline 6 & 1000 & 6 & 120 & 50 & 25 & 300 \\
\hline 7 & 1000 & 10 & 120 & 50 & 25 & 300 \\
\hline 8 & 1000 & 6 & 120 & 50 & 0 & - \\
\hline 9 & 1000 & 6 & 240 & 50 & 0 & - \\
\hline 10 & 1000 & 6 & 360 & 50 & 0 & - \\
\hline 11 & 1000 & 6 & 120 & 50 & 50 & 300 \\
\hline 12 & 1000 & 6 & 120 & 50 & 100 & 300 \\
\hline 13 & 2000 & 4 & 120 & 50 & 50 & 300 \\
\hline 14 & 2000 & 10 & 360 & 50 & 50 & 300 \\
\hline 15 & 2000 & 6 & 240 & 50 & 50 & 300 \\
\hline 16 & 2000 & 4 & 120 & 50 & 0 & - \\
\hline 17 & 2000 & 10 & 360 & 50 & 0 & - \\
\hline 18 & 1000 & 6 & 240 & 500 & 0 & - \\
\hline 19 & 1000 & 4 & 120 & 50 & 10 & 300 \\
\hline 20 & 1000 & 6 & 120 & 50 & 10 & 300 \\
\hline 21 & 1000 & 10 & 120 & 50 & 10 & 300 \\
\hline 22 & 1000 & 6 & 120 & 50 & 5 & 300 \\
\hline 23 & 1000 & 6 & 120 & 50 & 15 & 300 \\
\hline 24 & 2000 & 4 & 120 & 50 & 20 & 300 \\
\hline 25 & 2000 & 10 & 360 & 50 & 20 & 300 \\
\hline 26 & 2000 & 6 & 240 & 50 & 20 & 300 \\
\hline
\end{tabular}


TABELL 2 Time (s) to critical events

\begin{tabular}{|c|c|c|c|c|c|c|}
\hline $\begin{array}{l}\text { Run } \\
\mathrm{Nr}\end{array}$ & \multicolumn{2}{|c|}{ Smoke $3 \mathrm{~m}$ above floor } & $* *$ & $\begin{array}{l}600{ }^{\circ} \mathrm{C} \\
\text { smoke } \\
\text { DSLAYV }\end{array}$ & $\begin{array}{l}\text { in the } \\
\text { ayer } \\
\text { ASETB }\end{array}$ & $* *$ \\
\hline 1 & $100,340 *, 950 *$ & $30,330 *, 1030 *$ & $*-80$ & 1000 & 1120 & -120 \\
\hline 2 & $>1800$ & $>3700$ & & $>1800$ & 3730 & \\
\hline 3 & 100 & 1.30 & -30 & 930 & 885 & 45 \\
\hline 4 & 350 & 380 & -30 & $>1800$ & 2590 & \\
\hline 5 & $>1400$ & 1270 & & 1120 & 1240 & -120 \\
\hline 6 & 1540 & $>1400$ & & 1220 & 1340 & -120 \\
\hline 7 & $>1400$ & $>1500$ & & 1310 & 1430 & -120 \\
\hline 8 & 600 & 663 & -63 & 1200 & 1225 & -25 \\
\hline 9 & 820 & 900 & -80 & 2300 & 2230 & 70 \\
\hline 10 & 1050 & 1020 & 30 & $>2400$ & 3140 & \\
\hline 11 & to large $f$ & ire vent area & & & & \\
\hline 12 & -1 & $" \ldots$ & & & & \\
\hline 13 & $>1800$ & & & 1280 & 1290 & -10 \\
\hline 14 & $>1800$ & $>4500$ & & $>1800$ & 4480 & \\
\hline 15 & $>1800$ & $>2800$ & & $>1800$ & 2800 & \\
\hline 16 & 540 & 645 & -105 & 1110 & 1240 & -130 \\
\hline 17 & 1760 & 1980 & -220 & $>1800$ & 3760 & \\
\hline 18 & 420 & 490 & -70 & 1500 & 1410 & 90 \\
\hline 19 & 1180 & 1.050 & 130 & 1160 & 1175 & -15 \\
\hline 20 & 1380 & 1180 & 200 & 1240 & 1260 & -20 \\
\hline 21 & 1520 & 1270 & 250 & 1360 & 1355 & 5 \\
\hline 22 & 920 & 1000 & -80 & 1220 & 1225 & -5 \\
\hline 23 & 1440 & 1280 & 160 & 1260 & 1295 & -35 \\
\hline 24 & 1440 & 1235 & 205 & 1240 & 1240 & 0 \\
\hline 25 & $>1800$ & $>4160$ & & $>1800$ & 4160 & \\
\hline 26 & $>1800$ & 2680 & & $>1800$ & 2630 & \\
\hline$*$ & The smoke is mo & loving around $t$ & the $3-m$ & leve1 & & \\
\hline$* *$ & Difference in & calculated tim & nes beth & ween DSLA & YV and & SETB \\
\hline
\end{tabular}




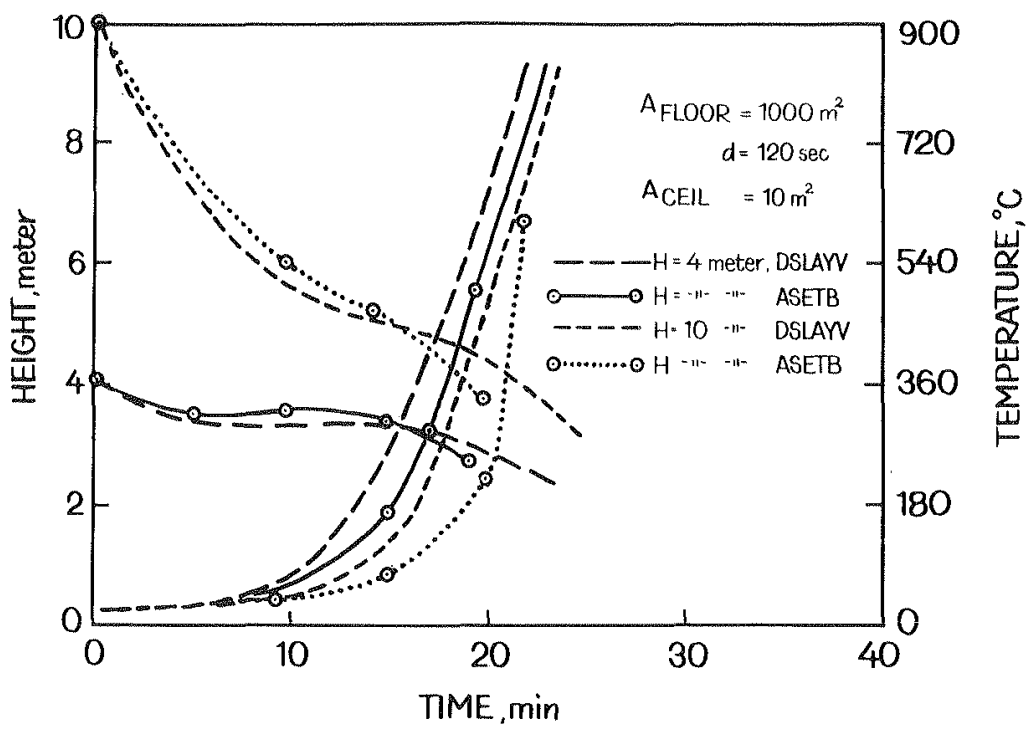

Fig. 4 Comparison between the level of the smoke and temperature calculated by DSLAYV and ASETB in runs 19 and 21.

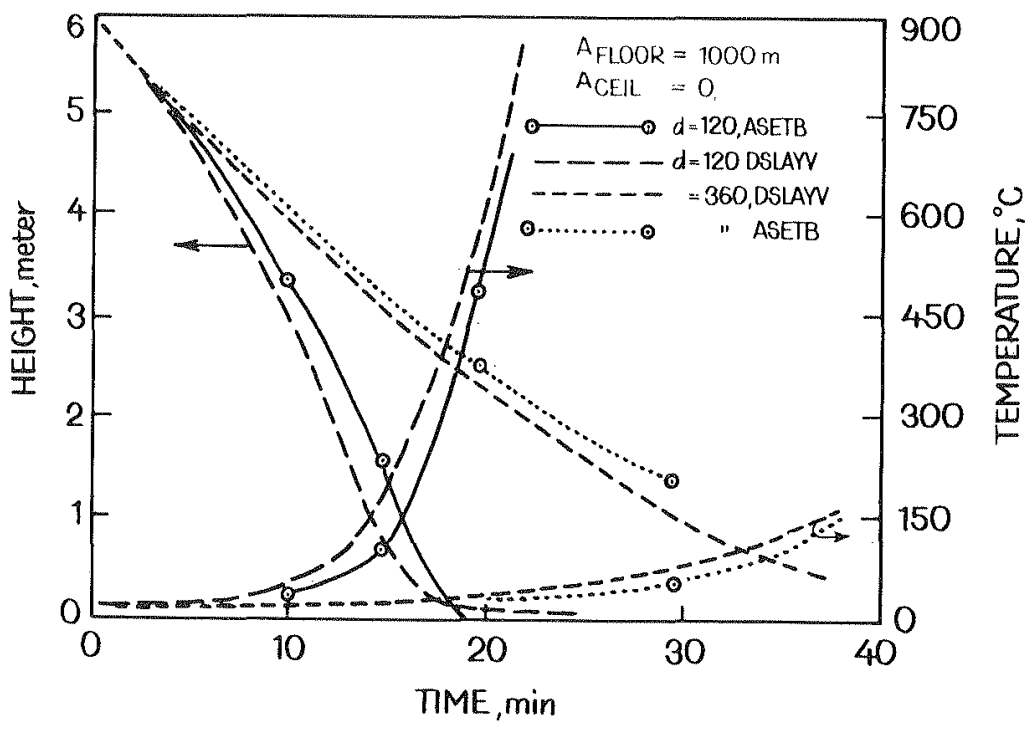

Fig. 5 Comparison between the level of the smoke and temperature calculated by DSLAYV and ASETB in runs 8 and 10 . 


\section{REFERENCES}

1 Cooper, L.; Estimating Safe Available Egress Time from Fires, Washington, NBSIR 80-2172, Center for Fire Research, National Bureau of Standards, 1981.

Walton, W.D.; ASET-B: A Room Fire Program For Personal Computer, NBSIR 85-3144-1, Center for Fire Research, National Bureau of Standards, December 1985.

DANISH FIRE PROTECTION ASSOCIATION; Fire Mode1 BRAND

4 Hägglund, B; Simulating fires in natural and forced ventilated enclosures. FOA, Stockholm, Report $C$ 20637-2.4, 1986 .

5 Bengtson, S., Hägglund, B.; The use of a Zone Model in Fire Engineering Application, The First International. Symposium on Fire Safety Science Gaithersburg, Md, USA. October 1985. 